\title{
Global Telecommunications Security: Effects of Geomagnetic Disturbances
}

\author{
doi:10.3991/ijim.v5i3.1667 \\ D.J. McManus ${ }^{1}$, H.H. Carr ${ }^{2}$, and B.M. Adams ${ }^{1}$ \\ ${ }^{1}$ The University of Alabama, Tuscaloosa, AL U.S.A. \\ ${ }^{2}$ Auburn University, Auburn, AL U.S.A.
}

\begin{abstract}
Global information and communication technologies permeate organizational structures, while questions of security pervade strategic plans of corporations worldwide. From the spectacular to the sublime, the effects of geomagnetic disturbances (i.e., electrical current produced by solar storms) can be as devastating to an organization's telecommunications systems as a hacker breaching a firewall. Using a dataset spanning 31 years (1978-2009) with 580,000 solar activity records, we investigate the effects and relationships of natural anomalies, specifically solar storms, on the security of corporate telecommunications. The ionosphere is a natural barrier around the earth to protect it from the sun and serve as a shield, but some electrical currents break this barrier causing significant telecommunications outages and security breaches within corporations. In this exploratory empirical study, we present the initial evidence that tracking geomagnetic disturbances can provide vital cautions for business continuity planning. The results of the study should help organizations with strategic planning efforts with respect to their overall security, especially as it relates to telecommunications.
\end{abstract}

Index Terms-Communication Systems, Information Technology, Risk Analysis, Solar Radiation, Organizational Security

\section{INTRODUCTION}

The adoption of global information and communications technologies is vital to the strategic plans of corporations worldwide, while the issue of secure data transmissions continues to plague network administrators. These administrators must consider all potential threats to their systems' vulnerabilities. One such threat comes from geomagnetic disturbances, as evidenced by solar storms (i.e., interactions of charged particles from the sun with the earth's atmosphere). These disturbances (or storms) are a direct result of solar flares or bursts of energy from the sun, which produce electromagnetic radiation across the electromagnetic spectrum at all wavelengths from long-wave radio to the shortest wavelength gamma rays [1]. These geomagnetic storms have been reported to cause problems for pipelines, electric power systems, and telecommunications networks. The costs associated with these storms can be significant. For example, an estimated $\$ 500$ million increase in the wholesale price of electricity resulted from solar storms, while government satellite disruptions average $\$ 100$ million per year [2, 3]. Computer and network administrators consider solar flares a double threat to telecommunications security due to the induction of electricity into wires and equipment, as well as, the interference with radio/wireless communications.
"Telephone and power lines continue to be strung on poles where they are susceptible to the inductive noise and even equipment damage from the solar flares. As early as 1859, telegraph systems were disabled by flares; nowadays, the induced energy might well disable a telephone central switch or computer modem. Areas of the country especially vulnerable are those with long-distance distribution lines as found in the northwest US and Canada. For the wireless environment, flares will add significant noise in the spectrum, making communications difficult and even disabling receivers" [1, p.234].

Although natural anomalies have affected communications systems over the past two centuries, the effects of electrical currents of solar storms, as seen in sunspots, can be as devastating to the security of an organization's telecommunications systems as a hacker breaching a firewall. In this research project, we conduct an exploratory empirical analysis of geomagnetic disturbances and their impact on communications systems.

\section{GeOMAGnEtic Disturbances}

The electrical "zaps" of the geomagnetic disturbances date back to the telegraph. Since the telegraph used long electrical conductors, it was the first system to be affected by solar storms. Interruptions caused by solar storms date back to 1848 , with an electrical telegraph anomaly between Florence and Pisa, Italy. It was not uncommon for the telegraph system to be unusable following such storms. Today, telegraph concerns are rare but many other wire-based systems are of vital interest. "On August 4, 1972 , an outage of the L4 coaxial cable system in the midwestern US occurred during a major geomagnetic disturbance. An examination of this disturbance showed that, at the time of the outage, the Earth's magnetic field had been severely compressed by the impact of high-speed particles from the Sun" [4, p. 2]. While the shielding of coaxial cables typically avoid such interferences, on this occasion, it was to no avail.

Solar storms continue to have an impact on continental cable systems, submarine cable systems and fiber optic cable systems, due to the induced voltages produced by geomagnetic disturbances. Although the fiber optic cabling is being used for transatlantic communication, there is still a conductor in the cable to carry power to the repeaters; hence, the electrical voltages from a solar event can still affect the communications signal. This event was duly noted in March 1989, when there was a geomagnetic storm that generated high voltage levels that affected the power supply cables. "Future cables, because of improvements in the fiber optics, may use fewer repeaters 
and require a lower driving voltage. However, downsizing the power feed equipment without taking account of the induced voltages may leave future systems more vulnerable to geomagnetic effects" [4, p. 2].

One of the best-documented solar disturbances occurred in China during June, 2000. China's Telecommunication Services experienced several geomagnetic disturbances over a two week period, with June $2^{\text {nd }}, 6^{\text {th }}$, and $9^{\text {th }}$ being the most notable. These solar storms have been credited with the interference of telecommunications services, i.e., shortwave radio services, communication satellites, and navigational systems, throughout the country for approximately 17 hours [5]. "Radio waves suffer lots of disturbances as a result of the irregular behaviour of ionosphere which is caused by erratic solar radiation from the sun" $[6$, p.114].

"During solar flare eruptions high-energy radiation, such as $x$-ray, and charged particles are hurled out of the Sun... when these particles and energetic radiation impact Earth, they may cause spectacular displays of aurora. However, the impact can create geomagnetic storms and deposit excess amounts of energy on satellite components and power grids, causing these systems to fail. Solar flares can also disrupt telecommunications, corrode pipelines, upset navigation systems, and pose radiation hazard to orbiting yuhangyuan (e.g,; astronauts in Chinese)" [5, p. 2].

These high energy charged particles in the solar winds can disturb the earth's barrier, which is important because the ionosphere reflects the High Frequency (HF) signals used by satellite communications and GPS navigation systems that support U.S. Department of Defense, emergency services, broadcasters, marine and aviation operators [4].

The allure of solar storms, i.e., Aurora Borealis or northern lights in the Northern Hemisphere, has been pondered for centuries. Benjamin Franklin first brought attention to the "mystery of the Northern Lights" in 1779, by theorizing that overcharged electrical charges illuminated the sky [7]. As presented in Table I, there is evidence that allows researchers to postulate that the aurora (i.e., the result of solar storms) indirectly affects electrical communication systems, that is, they are the evidence of charged particles.

\section{Global TeleCOMMUNICATIONS SECURITY}

Scientists believe that electromagnetic space storms will have a negative impact on telephone lines, television signals, aircraft navigation systems, and create widespread power outages $[6,10]$. Models have been developed to forecast average trends of solar storms [11, 12, 13]; however, as organizations conduct business continuity planning, they must understand the significant impact of all levels of solar storms to their telecommunications systems. Organizations certainly understand the effects of lightning from a thunderstorm; therefore, it is equally important for them to prepare for the potential degradation resulting from solar flares.

Geomagnetic disturbances, even when infrequent, can breach a corporation's telecommunications system, thus, putting the company at risk for a security breach. "The effects [of solar storms] may be particularly strong in high latitude(s), and trigger powerful currents in telephone and electrical equipments"'[6, p.116]. It is evident that modern
TABLE I.

HISTORICAL ACCOUNTS OF SOLAR EVENTS

\begin{tabular}{|c|c|}
\hline $\begin{array}{l}\text { Event } \\
\text { Date }\end{array}$ & GEOMAGNETIC DISTURBANCES \\
\hline $\begin{array}{l}\text { June } \\
15 \\
2000\end{array}$ & $\begin{array}{l}\text { China Telecom Services - Beginning June } 2,2000 \text { solar } \\
\text { storms are believed to be responsible for interfering with } \\
\text { telecommunications: June } 9 \text { - shortwave radio services } \\
\text { affected throughout China for } 17 \text { hours. The solar disturb- } \\
\text { ance interfered and interrupted a communication satellite } \\
\text { and some navigation related systems [5]. }\end{array}$ \\
\hline $\begin{array}{c}\text { March } \\
1989\end{array}$ & $\begin{array}{l}\text { Fiber Optic Cable - New submarine cables are using } \\
\text { optical fibers to carry the signals, but a conductor carries } \\
\text { the power to the repeaters. At the time of the storm, a new } \\
\text { transatlantic telecommunications fiber-optic cable was in } \\
\text { use and large induced voltages were observed on the } \\
\text { power supply cables [4]. }\end{array}$ \\
\hline $\begin{array}{c}\text { Aug. 4, } \\
1972\end{array}$ & $\begin{array}{l}\text { Coaxial Cable - An outage of the L4 coaxial cable system } \\
\text { in the mid-western US occurred during a major geomag- } \\
\text { netic disturbance [4]. }\end{array}$ \\
\hline $\begin{array}{c}\text { Feb. 10, } \\
1958\end{array}$ & $\begin{array}{l}\text { Submarine Cable System - Transatlantic communication } \\
\text { from Clarenville, Newfoundland, to Oban, Scotland } \\
\text { proceeded as alternately loud squawks and faint whispers } \\
\text { as the naturally induced voltage acted with or against the } \\
\text { cable supply voltage [4]. }\end{array}$ \\
\hline $\begin{array}{l}\text { Mar. } \\
24 \\
1940\end{array}$ & $\begin{array}{l}\text { Early phone system - Phone communications in the US } \\
\text { were disrupted and voltages in excess of } 500 \mathrm{~V} \text { were } \\
\text { thought to have occurred. In Sweden, several magnetic } \\
\text { storms produced voltages large enough to start arcing in } \\
\text { the carbon protectors, ultimately resulting in fire [4]. }\end{array}$ \\
\hline $\begin{array}{c}\text { Feb. 19, } \\
1852\end{array}$ & $\begin{array}{l}\text { Chemical Telegraph - Bain's "chemical telegraph" used } \\
\text { specially prepared paper: current from a stylus caused a } \\
\text { chemical reaction leaving a coloured mark on the paper. } \\
\text { Electrical current increased so much that a "flame of fire" } \\
\text { followed the pen and set fire to the paper [4]. }\end{array}$ \\
\hline $\begin{array}{c}\text { Sept., } \\
1851\end{array}$ & $\begin{array}{l}\text { New England, United States - A solar storm occurred and } \\
\text { took complete possession of all the telegraph lines in New } \\
\text { England and prevented any business from being transacted } \\
\text { during its duration [8]. }\end{array}$ \\
\hline $\begin{array}{l}\text { Nov. } \\
17 \\
1848\end{array}$ & $\begin{array}{l}\text { Electric Telegraph in Italy - A man named Matteucci had } \\
\text { the opportunity to observe the magnetic influence of } \\
\text { geomagnetic disturbances. The soft iron armatures em- } \\
\text { ployed in the electric telegraph between Florence and Pisa } \\
\text { remained attached to their electro-magnets, as if the latter } \\
\text { were powerfully magnetized, without the apparatus being } \\
\text { in action and without the currents in the battery being set } \\
\text { in action [9]. }\end{array}$ \\
\hline $\begin{array}{l}\text { Nov. } \\
17 \\
1848\end{array}$ & $\begin{array}{l}\text { Electric Telegraph in England, a man named Highton } \\
\text { witnessed a strange event - the magnetized needle of the } \\
\text { electric telegraph was always driven toward the same side, } \\
\text { even with much force [9]. }\end{array}$ \\
\hline $\begin{array}{l}\text { April } \\
14 \\
1779\end{array}$ & $\begin{array}{l}\text { Benjamin Franklin's interest in the mystery of Solar } \\
\text { Storms (i.e., Aurora Borealis or Northern Lights) begun on } \\
\text { his voyages across the North Atlantic to England. He } \\
\text { ascribed the shifting lights to a concentration of electrical } \\
\text { charges in the polar regions intensified by the snow and } \\
\text { other moisture. He reasoned that this overcharging caused } \\
\text { a release of electrical illumination into the air. In this } \\
\text { essay, which he wrote in English and French, Franklin } \\
\text { analyzed the causes of these geomagnetic disturbances. It } \\
\text { was read at the French Académie des Sciences on April } \\
14,1779 \text { [7]. }\end{array}$ \\
\hline
\end{tabular}

technologies are adversely affected by solar storms, thus, organizations must recognize the need for a business continuity plan that can address wired and wireless environments. As companies review their global locations, consideration must be given to the impact of solar disturbances in a specific region of the world during a specificseason, time of day, and/or magnetic latitude. Organizations that have worldwide locations have increased vul- 
nerability to solar activities as global divisions will be affected as the earth turns. Business continuity plans must be developed to include the necessary risk assessment and appropriate response to geomagnetic disturbances that result in telecommunications outages.

\section{RESEARCH Methodology}

The National Oceanic and Atmospheric Administration (NOAA) Polar Operational Environmental Satellites (POES) track the daily activity levels of electromagnetic activity with specific focus on our Sun. This empirical data includes approximately 580,000 observations (i.e., activity records) for the years 1978-2009. POES monitors the power flux of the sun-producing protons and electrons, thus, using the power flux measurements to determine the total power input in a specific polar region [14]. These measurements are based upon an activity index, results of 100,000 satellite passes, ranging from 1 to 10 , where 10 is the highest; the total power dissipation is measured in gigawatts. We extrapolated the activity data from the NOAA POES to determine trends based upon historical events.

For each instance of data, the power and corresponding activity level are tracked, as well as the date, center time, hemisphere, satellite, and normalization factor. The center time is the time when the satellite is halfway complete in the pass over the pole; the hemisphere distinguishes whether the data was taken from the northern or southern hemisphere; the satellite is determined by the satellite number recording the event; and the normalization factor (n) represents the level of confidence in the estimate of power. A normalization factor value of 2.0 or less for $n$ signifies strong confidence, while a value of 2.0 or greater means there should be less confidence in the power and activity level measurements [14].

During our preliminary investigation, we evaluated data relating to historical geomagnetic disturbances that have impacted telecommunications systems throughout the world. Our purpose was to analyze individual known events, such as those reported in Table 1. In this stage of the research project, statistical analyses were conducted in an attempt to evaluate the relationships of historical events and geomagnetic disturbances occurring during reported outages, which are attributed to solar storms. We focus our findings, in this preliminary stage, on the events of the China Telecommunications services outages in June, 2000. The geomagnetic disturbances beginning June 2, with additional storms on June $6^{\text {th }}$ and June $9^{\text {th }}$ are clear indicators that solar storms can significantly impact telecommunications equipment and services as well as shortwave radio service. The most serious of these three events, interfering with the China telecommunications systems, occurred on June $9^{\text {th }}$, resulting in an outage of 17 hours, with interruptions to communication satellites and navigational systems. These geomagnetic disturbances were well documented by NOAA POES, including timeline and activity level of the solar storms.

\section{DISCUSSION}

In our preliminary investigation, the activity level of the solar storms for June, 2000 was evaluated by conducting a time series analysis using the measurement of gigawatt power. Figure 1 reports the findings of this statistical process for June 1-4, 2000 in the Northern Hemisphere. The disturbance in China was reported approximately
$3: 30 \mathrm{pm}$ (local time). This timeline would correspond to approximately 2:30 a.m. in North America and 9:30 a.m. in Europe. As indicated in Figure 1, there is clear evidence of a significant magnetic disturbance, (i.e., during early morning of June $2^{\text {nd }}$ ). In addition, the solar storm is stronger during the summer months; thus, the reported disruptions in China were at maximum strength, resulting in significant outages.

Based upon the results in Figure 1, a closer examination was warranted, so a time series plot is provided for June 12, 2000, as shown in Figure 2. Observations 29 and 37 become more evident; however, one should question the impact of observation 37, with a value of 195. Based upon the criteria presented by NOAA POES, observation 37 has a quality reading of $n>4$ indicating that there is less confidence in the reliability of the measurement. Observation 29 , with a value of 101.2, has a quality measure of $n=1.2$ indicating a very reliable measurement. Although there is less confidence in the reliability of observation 37 , there is clear evidence that a geomagnetic disturbance occurred that had a significant impact on the country of China.

Furthermore, Figure 3 presents a histogram of gigawatt power readings by hemisphere for all data collected in the year 2000. The overall distributions of the power measurements are skewed; however, these readings, and any resulting actions, must be tempered by the quality of the measurements as determined by $\mathrm{n}$. This is the juncture where thresholds for threat levels need to be established and perhaps establishing boundaries for Level 1, 2, or 3 emergency recovery plans.

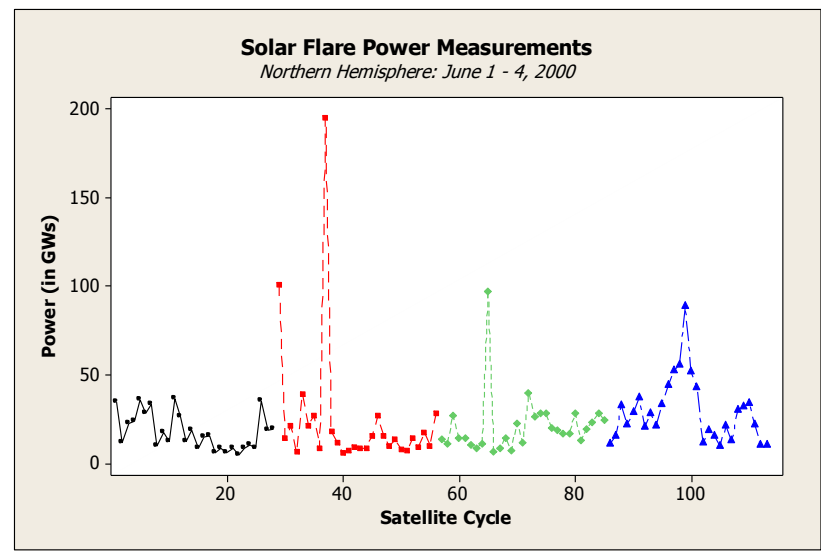

Figure 1. Solar Flare Power Measurements - Northern Hemisphere: June 1- June 4, 2000

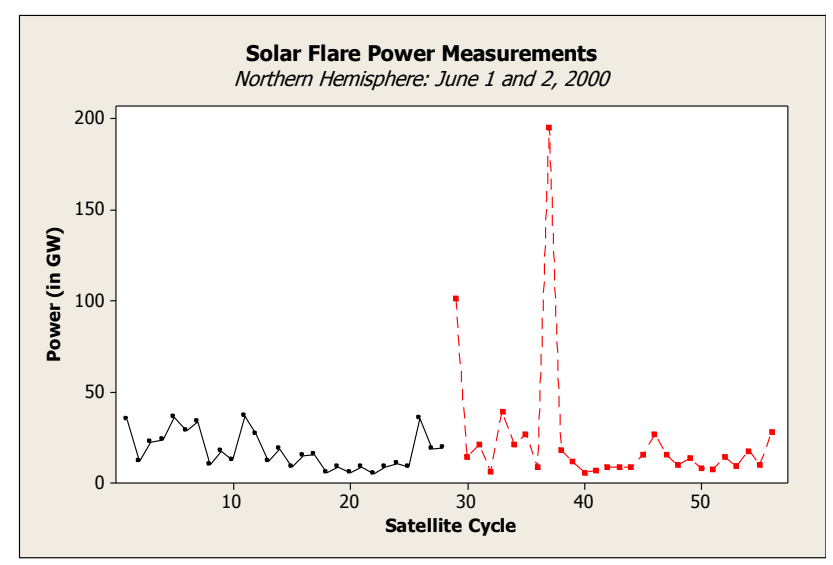

Figure 2. Solar Flare Power Measurements - Northern Hemisphere: June 1 and June 2, 2000 


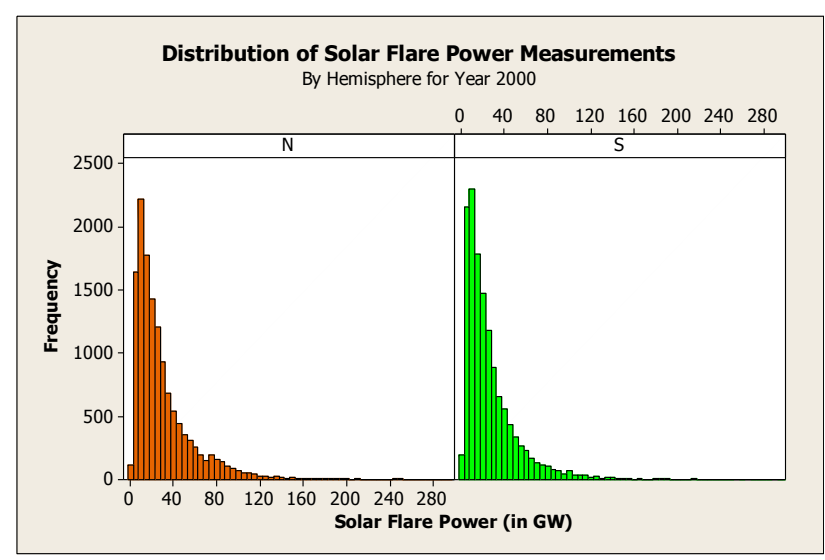

Figure 3. Distribution of Solar Flare Power Measurements - By Hemisphere (Northern and Southern) for Year 2000

Power readings for June $6^{\text {th }}$ and June $7^{\text {th }}, 2000$ are reported, by hemisphere, in Figures $4 \mathrm{a}$ and $4 \mathrm{~b}$. On both of these days major solar storm activity was experienced and significantly impacted Chinese telecommunications services. It should be noted that the impact of solar storms may potentially be influenced by a number of factors such as the season (i.e., tilt of the earth's axis), time of day (i.e., earth's orientation to the sun), altitude, or latitude. In both cases, China is protected from solar events by the earth's rotation, which could explain the lack of disruption in the Chinese infrastructure. As noted in Figures $4 \mathrm{a}$ and $4 \mathrm{~b}$, solar disturbances may impact different hemispheres with varying degrees; hence, this should be considered in evaluating business continuity planning.

The power measurements reported in Figure 5 certainly correspond with the short wave radio, communication satellite and navigational system disruptions, experienced in China on June $9^{\text {th }}$ and $10^{\text {th }}, 2000$. There is clear evidence that the Northern Hemisphere experienced extremely strong geomagnetic disturbances that coincided with outages of 17 hours. In a comparison of the solar storm activity levels on these two days with June $2^{\text {nd }}, 6^{\text {th }}$, and $9^{\text {th }}$, it is important to note the relative severity of the power measurements and severity of the outage.

NOAA POES recorded the eruptions on the Sun during this reported outage. These events caused by an M-class flare at 3:00 p.m. on June $2^{\text {nd }}$ affected the southern region of China, such as Guangzhou, Hong Kong and Haikou. The second geomagnetic disturbance event was recorded approximately midnight on June $6^{\text {th }}$, resulting from two Xclass flares that produced large amounts of charged particles. Fortunately, since this event occurred at night, the country of China was facing in the opposite direction away from the high energy radiation. However, two days later on June 9, during a daylight event, charged particles slammed into the Earth's atmosphere and caused a severe storm in the ionosphere, resulting in wide spread disruption to shortwave radio services and other communications systems [5]. These coinciding events provided strong evidence that the geomagnetic disturbances can impact organizations worldwide. Therefore, the academicians of twenty research units associated with the Chinese Academy of Sciences joined together to develop a 15-year Space Weather Strategic Plan [5]. It is projected that more geomagnetic disturbances will occur, which necessitates the need for organizations to include in their business continuity plan recovery strategies for geomagnetic disturbances;

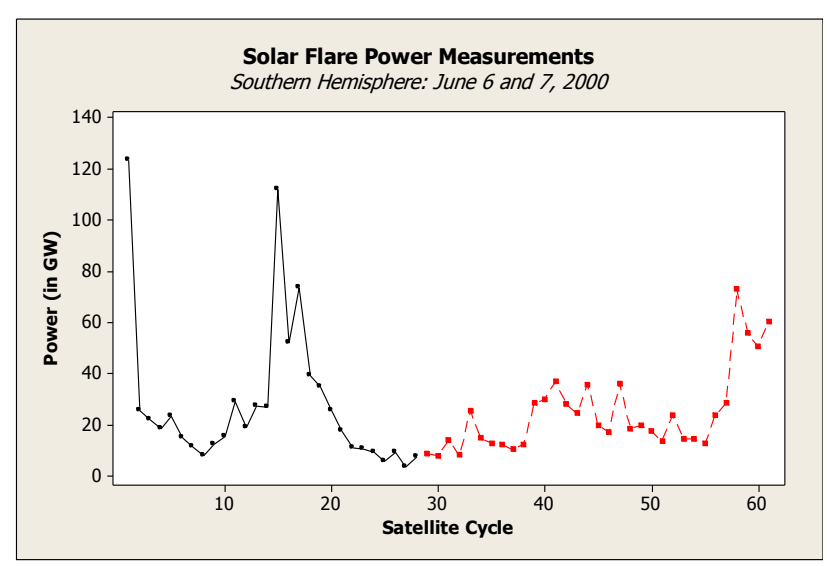

Figure 4a - Solar Flare Power Measurements - Southern Hemisphere: June 6 and June 7, 2000

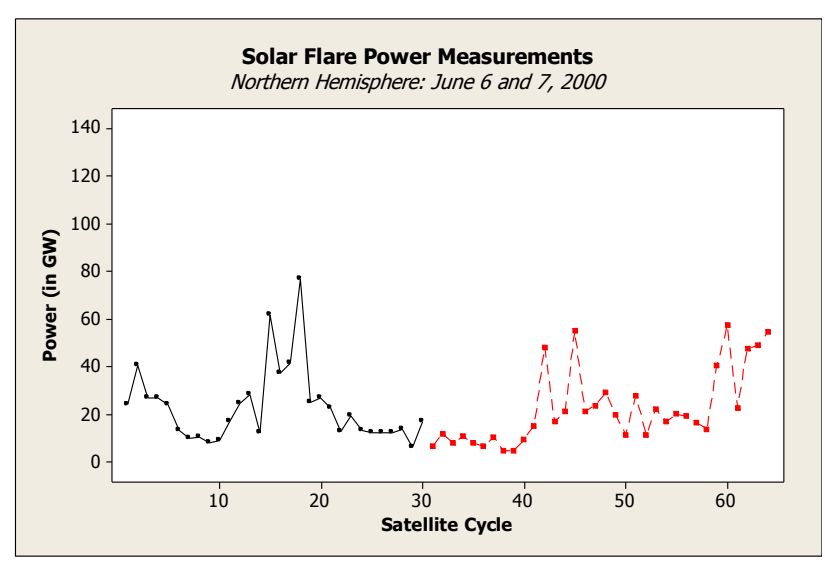

Figure $4 \mathrm{~b}$ - Solar Flare Power Measurements - Northern Hemisphere: June 6 and June 7, 2000

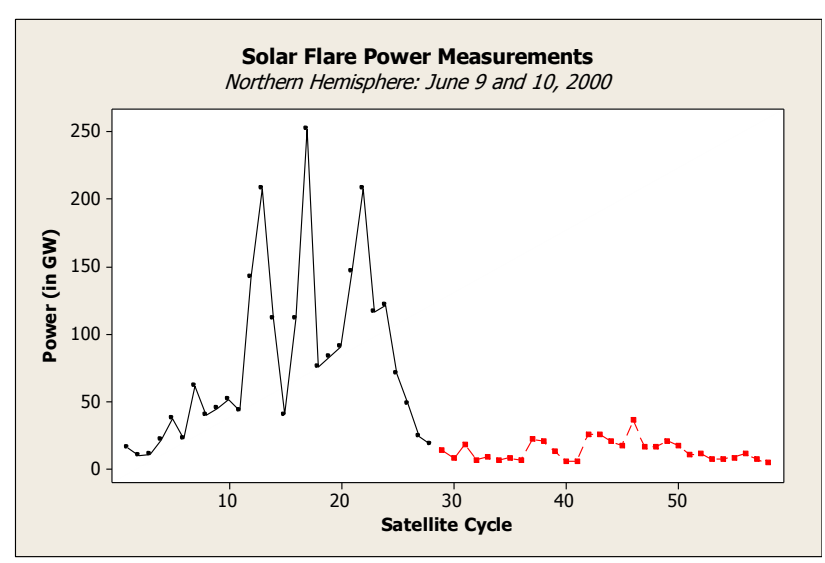

Figure 5. Solar Flares Power Measurements - Northern Hemisphere: June 9 and June 10, 2000

thus, protecting the integrity of their telecommunication systems.

The initial results from this research provide evidence that by using satellite readings of gigawatt power measurements, one can determine reasonable guidelines for Emergency Response Activity thresholds or threat levels. These thresholds or threat levels might be a function of location measures (e.g., magnetic latitudes, hemisphere), local time (e.g., am, pm), and altitude of city or region.

The development of predictive models to provide early warnings of threats would aid emergency response efforts. One approach is directly modeling the intensity of solar 


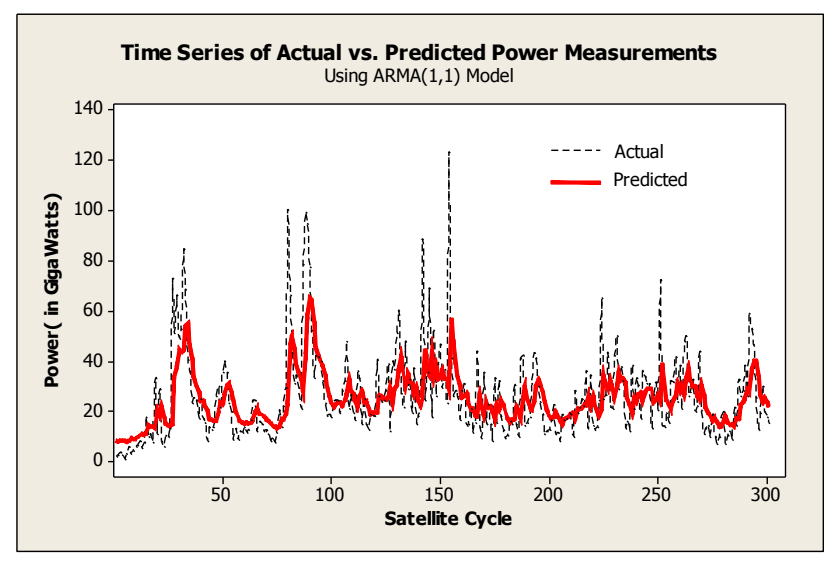

Figure 6. Solar Flares Power Measurements - Northern Hemisphere: Actual vs. Predicted

flares. As represented in Figure 6, a sequence of 800 consecutive satellite readings are modeled using an autoregressive moving average (ARMA) model of order $(1,1)$. The actual observations are depicted by the smaller dashed lines while the predicted values are represented by the bold lines.

The ARMA $(1,1)$ parameters were all statistically significant $(\mathrm{p}<0.005)$ as illustrated in Table II. While the predicted values reflect the average trend in solar flare activity, the extreme values are consistently underestimated. Predicting trends in solar flare activity is important but the extreme values are the source of threats to telecommunication infrastructure.

TABLE II.

STATISTICAL TEST OF ARMA $(1,1)$

FINAL PARAMETER ESTIMATES

\begin{tabular}{|l|c|c|c|c|}
\hline \multicolumn{1}{|c|}{ Type } & Coef & SE Coef & T & P \\
\hline AR 1 & 0.8880 & 0.0259 & 34.22 & 0.000 \\
\hline MA 1 & 0.5846 & 0.0457 & 12.79 & 0.000 \\
\hline Constant & 2.5839 & 0.2145 & 12.04 & 0.000 \\
\hline Mean & 23.075 & 1.916 & & \\
\hline
\end{tabular}

A second approach is to model the threat level using a scale of 0 to 1 with zero (0) indicating no threat of disruption and one (1) indicating a significant disruption due to solar activity, such as the China solar event. Two potential predictive models are logistic regression models and neural networks. In the case of logistic regression, exogenous variables result in prediction values in the interval $[0,1]$ which have nice probabilistic interpretations. The simplest form of the logistic regression model is given by

$$
E(Y)=\frac{\exp \left(\beta_{0}+\beta_{1} X\right)}{1+\exp \left(\beta_{0}+\beta_{1} X\right)}
$$

where $\mathrm{E}(\mathrm{Y})$ represents the expected value of the response variable (probability of a solar event) and $\mathrm{X}$ represents some exogenous variable. Figure 7 provides an illustrative graphical display of a logistic regression curve with $\beta_{0}=-10$ and $\beta_{1}=0.1$. Note that as the value of $\mathrm{X}$ increase from 50 to 150 , the estimated likelihood of a solar event increases from nearly zero to nearly one. In future research, we will attempt to develop practical prediction models using the findings of this initial investigation.

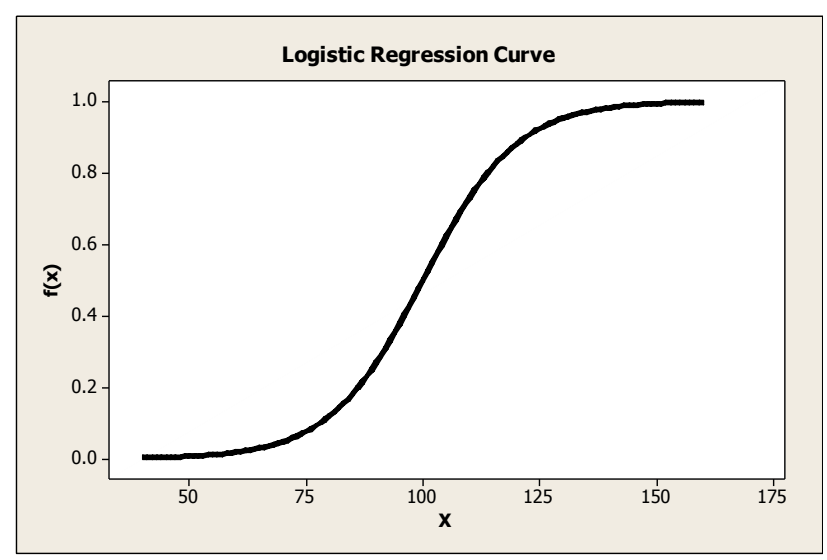

Figure 7. Illustrative Logistic Regression Curve for Modeling the Likelihood of Events

Additional input variables such as the presence of coronal mass ejections (CME), magnetic orientation of CME, and infrastructure location (longitude, latitude, elevation) are being evaluated as part of on-going research.

To date, the prediction of solar flares and geomagnetic disturbances are limited at best; however, by tracking the intensity of solar disruptions, we have the opportunity to predict potential dangerous outages. Companies may then assess potential costs of disruptions and reasonable counter measures for maintaining viable operations at the predicted threat level. As companies review their global locations, consideration must be given to the impact of geomagnetic disturbances in a specific region of the world during a specific season, time of day, and latitude.

\section{CONCLUSIONS}

Globalized corporations depend upon information and communication technologies as a component of their strategic plans; hence, deciphering and mitigating risk to these technologies is vital to corporate business continuity plans. The International Telecommunication Union has reported in the year 2010, there are five billion mobile devices worldwide. Just imagine the 6.8 billion people on our planet without mobile devices. As companies review their global locations, consideration must be given to the impact of geomagnetic disturbances in a specific region of the world during a specific season, time of day, and latitude. Business continuity plans must be developed to include the necessary risk assessment and appropriate response to geomagnetic disturbances that result in information technology outages.

\section{ACKNOWLEDGMENTS}

We would like to acknowledge and thank National Oceanic and Atmospheric Administration (NOAA) Polar Operational Environmental Satellites (POES) for their continued collection and sharing of solar activity and data sources. In addition, we would like to thank our student, Kristina Dueland for her efforts during the preliminary stages of our research. An earlier version of this research was presented at the 2010 Interdisciplinary Conference of AHLiST, Association of History, Literature, Science and Technology. 


\section{Global Telecommunications SeCURITy: EFFECts of GeOMAGNETiC Disturbances}

\section{REFERENCES}

[1] H. H. Carr, C. A. Snyder and B. N. Bailey, The Management of Network Security: Technology, Design, and Management Control. 1st ed., Pearson/Prentice/Hall, 2010.

[2] S.F. Oldenwald and J.L. Green, "Bracing the Satellite Infrastructure for a Solar Superstorm," Scientific American Magazine, August 2008.

[3] Data Users. NOAA Economics; The Economic and Social Benefits of NOAA Data \& Products. Weather and Water, (2009), 1-2. (http://www.economics.noaa.gov) [accessed May, 2010].

[4] Space Weather Canada, "Geomagnetic effects on communication cables," Government of Canada, (http://www.spaceweather.gc.ca/ cable_e.php), [accessed November 2009].

[5] W. Long, "Solarstorms impact China's telecom services." SpaceDaily, 15 June 2000, (http://www.spacedaily.com/news/ solarstorm-00f.html.), [accessed November, 2009].

[6] B.A. Ezekoye and R. M. Obodo, "The effects of solar radiations on telecommunications", Pacific Journal of Science and Technology, 8(1), pp. 109-117, 2007.

[7] Library of Congress, "Benjamin Franklin in his own words", Library of Congress, Exhibitions, American Treasures, 2006 (http://www.loc.gov/exhibits/treasures/franklin), [accessed November 2009].

[8] G. B. Prescott, "United States early radio history - telegraph", History, Theory and Practice of the Electric Telegraph, pp. 318326, 1860.

[9] P. Norton, "The Aurora Borealis and the Telegraph", 2007, (http://www.rainbowriderstradingpost.com/article1.html), [accessed October 2009]
[10] McManus, D.J., Carr. H.H., and Adams, B.A. Wireless on the Precipice: The Fourteenth Century Revisited. Communications of the ACM. June, 2011.

[11] Dikpati, M., deToma, G. and Gilman, P. Predicting the Strength of Solar Cycle 24 Using a Flux Transport Dynamo-based Tool. Geophysical Research Letters, 33, L05102, (Sept. 2006), doi:10.1029/2005GL025221.

[12] Hathaway, D. and Wilson, R. Geomagnetic Activity Indicates Large Amplitude for Sunspot Cycle 24, Geophysical Research Letters, 33, L18101, (Sept., 2006), doi:10.1029/2006GL027053.

[13] Hathaway, D. Solar Cycle Prediction. NASA/Marshall Solar Physics, (May, 2010), (http:// solarscience.msfc.nasa.gov/predict. html) [accessed May, 2010].

[14] J. Green and L.Puga, "Introduction - auroral activity extrapolated from NOAA POES", 2007, Space Weather Prediction Center, (http://www.swpc.noaa.gov/pmap/Intro.html), [accessed October 2008].

\section{AUTHORS}

D. J. McManus is with The University of Alabama, Tuscaloosa, Alabama, 35487 USA (e-mail: dmcmanus@cba.ua.edu).

H. H. Carr is with Auburn University. Auburn, Alabama 36849 USA (e-mail: Houston@business.auburn.edu).

B. M. Adams is with The University of Alabama, Tuscaloosa, Alabama, 35487 USA (e-mail: badams@ @ba.ua.edu).

This article is an extended version of a paper presented at the Interdisciplinary Conference of AHLiST 2010 Conference, June 2010, Madrid, Spain. Received May th, 2011. Published as resubmitted by the authors June $9^{\text {th }}, 2011$. 